\title{
Attitudinal Analysis of President Xi's Remarks at Press Conference of BRICS Xiamen Summit from the Perspective of Appraisal Theory
}

\author{
Yuyu Zhang \\ Shanxi Normal University, China
}

\begin{abstract}
The Appraisal Theory that is the development of interpersonal meaning is divided into Attitudinal resources, Engagement resources and Graduation ones, and its core is the Attitudinal resources. In recent years, the appraisal theory has been employed by many scholars in the field of linguistics. This paper mainly employs attitudinal system to analyze the president Xi's remarks at the Press Conference of BRICS Xiamen Summit by the way of qualitative and quantitative researches. President Xi's remarks are significant and meaningful for the continually cooperation of BRICS. It is found that attitudinal resources are widely distributed in the remark, and they are unevenly applied. Positive attitudinal resources far exceed the negative ones, while direct attitudinal resources overweight the implied ones. What is more, the affect's distribution is the least and the appreciation is far beyond affect and judgment. The paper analyzes the distribution of attitudinal resources in this remark in order to show China's friendly relationship with other countries and China's determination to strengthen international cooperation and common development.
\end{abstract}

Index Terms-Appraisal Theory, attitudinal system, President Xi's remarks, BRICS Xiamen Summit

\section{INTRODUCTION}

Following Halliday's the Systemic Functional Grammar, Martin and White put forward the appraisal theory including attitude, engagement and graduation resources, which developed the meaning of interpersonal function of Halliday. Halliday once put forward that language carries three kinds of meta-functions, ideational function, interpersonal function and textual function. The work on Appraisal Theory by Martin and his colleagues (Martin 2000; Martin \& Rose 2003) provides a systemic framework for the analysis of attitude in systemic functional linguistics at a discourse semantic level. At the same time, the appraisal theory has attracted more attention in the kinds of fields of researches. Li Zhanzi (2002) applies Appraisal Theory to discourse analysis and points out the problems in the process of applying the Appraisal System into the analysis of commercial advertising utterances, historical utterances and autobiographical utterances. The problems are: the interpersonal function of attitude should be emphasized further; the importance of the context in recognizing evaluation means should be paid special attention to; the border-line between evaluation as interpersonal meaning and ideational meaning should be made clear; the relationship between evaluation and register should be made clear too. Wang Zhenhua makes a series of research on applying the appraisal system into discourse analysis: 1) He makes the study of engagement in essays (Wang, 2001), and gives an exact illustration of the sources of attitude, namely, engagement on the basis of the analysis of the Chinese corpus; 2) He researches on emotion and engagement (Wang, 2001) and concludes that emotion plays an important role in the representation of interpersonal meaning; 3) He makes a study of Attitude in hard news (Wang, 2001) and concludes that judgment is adopted more than affect and appreciation in English and Chinese hard news based on the analysis of attitudes in English and Chinese newspaper. Wang yuelu (2006) made the attitudinal analysis of VOA and BBC news report in the light of appraisal theory. She carried out the contrast between the attitudinal resources of VOA and BBC news report in the thesis. Li Chengchen and Jiang Guiying (2017) made the comparison of Chinese and English other narration of academic monograph from the point of the appraisal theory. This research compared the differences between Chinese and English attitudinal resources' distribution characteristics of 60 discourses by the way of SPSS 22.0. Meanwhile, appraisal theory provides new points of view for foreign language practices, translation practices, etc. Besides, appraisal theory also provides theoretical framework for kinds of written and oral discourse researches, for example, commercial discourse, literature works, speeches, etc. Different discourse applied the appraisal theory from different aspects.

In the August of 2017, the $9^{\text {th }}$ BRICS Summit has been conducted in Xiamen, China. The BRICS refers to the five countries, Brazil, Russia, India, China and South Africa. Why are they called BRICS countries? The reason is that these five countries have developed rapidly in the recent years and have a huge potential in the world's market. Brazil is the agricultural country storing amount of oil, Russia is the big country of resources, and India is the large country of agriculture, and population. Besides, the South Africa is a country possessing rich mineral resources. Therefore, their cooperation will be beneficial for economic, political, cultural and ecological development of five countries and many countries around the world. This year, China as the chairman country will enhance exchanges in humanistic sectors and push political security and economic development of five countries. The BRICS Summit has been held nine times and 
held in different regions. The first was in Russia, the second in Brazil, the third in China and the ninth is also in China. On October 16, 2016, President Xi Jinping at the eighth meeting of the leaders of the BRIC countries in Goa, India, said that Xiamen, Fujian Province will hold the ninth meeting of the BRICS leaders in September next year. At the same time, China will try continually to strengthen the representativeness and influence force of the BRICS. The convening of the BRICS National Conference has led to the gradual formation of the "BRICS" cooperation mechanism, and the international influence of the "BRICS" as the representative of the global emerging economies is also increasing. According to the International Monetary Fund in October 2010 released the "International Economic Outlook" and the market exchange rate estimates, "BRIC" GDP from 2008 will account for $15 \%$ of the world's share rose to $22 \%$ in 2015 , then the total economic output of the four countries will exceed the United States, while the four countries GDP growth will account for one-third of the world's increment. Therefore, the remarks of president Xi at Press Conference of BRICS Xiamen Summit are significant and meaningful for the development of their relationship.

\section{The ATtitudinAl System OF APPRAISAL THEORY}

The Appraisal Theory is concerned with evaluation: the kinds of attitudes that are negotiated in a text, the strength of the feelings involved and the ways in which values are sourced and readers aligned (Martin \& White, 2008). That is to say, the Appraisal Theory is composed of three parts, attitude, engagement and graduation. During the framework of Appraisal Theory, attitude is the core system. It is used to source feelings and grade feelings, through which engagement and graduation are able to be specified respectively. Engagement is the source of attitude concerned with the matter how attitude resources are negotiated in a community. Graduation is the strength of attitude, modifying attitude resources by ways of force and focus. The attitude resource including affect, judgment and appreciation is the core system of the Appraisal Theory. Attitude resource can be coded implicitly and explicitly indicating positive or negative meaning. Attitude is a way of expressing the person's feelings and ideology. And affect is at the heart of the three sub-systems because it is the expressive resources that we are born with. One way to think about judgment and appreciation is to see them as institutionalized feelings, which take us out of our everyday common sense world into the uncommon sense worlds of shared community values (Martin \& White, 2008). The details of Attitude will be introduced in the following. Figure 2 is an outline to illustrate affect as the heart of institutionalized feelings.

Ethics/morality (rules and regulations)

Feeling institutionalized as proposals

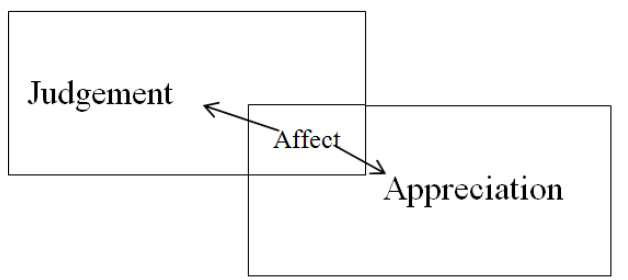

Feeling institutionalised as propositions aesthetics/value(criteria and assessment)

Figure2 Judgement and appreciation as institutionalised affect(Martin,2008)

\section{A. Affect}

Affect involves three semantic regions, which is traditionally referred to as emotion, ethics and aesthetics. Emotion is arguably at the heart of these regions since it is the expressive resource we are born with and embodies physiologically from almost the moment of its birth (Painter, 2003). Affect is concerned with registering positive and negative feelings: do we feel happy or sad, confident or anxious, interested or bored (Martin \& White, 2008). Generally speaking, affect can be achieved through affective adjectives, affective verbs, affective adverbs, etc. In terms of the classifications, six factors can be applied, positive and negative affect, behavior surge and mental state, directed and undirected, low and high, realis and irrealis, and un/happiness, in/security, and dis/satisfaction.

\section{B. Judgment}

Judgment, as a subsystem of Affect, is used to evaluate one's behavior or character, which we admire, praise or condemn according to a set of social norms, which include rules, conventions, social acceptability, social requirements of expectations and systems of value. It involves whether the attitudinal evaluation is negatively or positively assessed with reference to one's behavior, state of affairs by social norms. We may assess one's behavior as moral or immoral, legal or illegal, socially acceptable or unacceptable, as commendable or condemnable, normal or abnormal and so on. Judgment resource is the evaluation of the person's behavior, which consists of social esteem and social sanction. Social esteem have to do with normality (how unusual someone is), capacity (how capable they are) and tenacity ( how resolute they are); social sanction have to do with veracity(how truthful someone is) and propriety( how ethical someone is) (Martin \& White, 2008). 


\section{Appreciation}

Appreciation resource is the evaluation of the natural phenomenon, concrete or abstract thing, etc. which is composed of three parts, reaction, composition and valuation. The reaction refers to whether they catch our attention or not, and whether we like them or not. The composition is the things' balance and complexity. What is more, the valuation how they are innovative, authentic or timely. As with affect and judgment, we can recognize positive and negative evaluations-properties we value alongside those we do not. Table 2.3 is the types of appreciation resources.

TABLE 2.3

TYPES OF APPRECIATION (MARTIN \& WHITE, 2008)

\begin{tabular}{|l|l|l|}
\hline \multicolumn{2}{|c|}{ Positive } & negative \\
\hline Reaction: & Arresting, engaging... & Dull, boring, tedious... \\
Impact: did it grab me & Fascinating, exciting... & Dry, ascetic, uninviting... \\
\hline Reaction: & Okay, fine, good... & Bad, nasty, yuk... \\
Quality: did I like it & Lovely, beautiful... & Plain, ugly, grotesque... \\
\hline Composition: & Balanced, harmonious... & Unbalanced, discordant... \\
Balance: did it hang together & Symmetrical, logical... & Shapeless, distorted... \\
& Consistent, considered... & Uneven... \\
\hline Composition: & Simple, pure, elegant... & Ornate, unclear... \\
Complexity & Lucid, clear... & Plain, monolithic... \\
\hline Valuation & Penetrating, profound... & Shallow, reductive... \\
Was it worthwhile & Innovative, original... & Conventional... \\
\hline
\end{tabular}

\section{The Analysis of Attitudinal Resources}

As we all know, attitudinal resources are composed of affect, judgment and appreciation. Through the analysis of President Xi's Remarks at Press Conference of BRICS Xiamen Summit, we get a large number of attitudinal resources applied in this remark. We can gain some knowledge and ideology about economic cooperation and the relationship of BRICS through the analysis of attitudinal resources towards the remarks at Press Conference of BRICS Xiamen Summit. The following is the distribution of attitudinal resources including affect, judgment and appreciation respectively.

TABLE3.

THE PROPORTION OF THE ATTITUDINAL RESOURCES

\begin{tabular}{|l|l|l|l|l|}
\hline Value & affect & judgment & appreciation & total \\
\hline Occurrence & 14 & 22 & 45 & 81 \\
\hline Proportion & $17.3 \%$ & $27.1 \%$ & $55.6 \%$ & $100 \%$ \\
\hline
\end{tabular}

Table3 is the distribution of attitudinal resources, affect, judgment and appreciation respectively. A total amount of attitudinal in this text is 81 , of which have 14 affect, 22 judgment and 45 appreciation resources. In addition, affect accounts for $17.3 \%$, judgment takes up $27.1 \%$ and appreciation occupies $55.6 \%$. Therefore, the most attitudinal resources in this text are appreciation and the least are the affect. So in the public speech, remarks and conferences, we are supposed to try to lessen the express of personal feelings and employ the positive evaluation.

A. The Analysis of Affect

TABLE3.1

THE DISTRIBUTION OF AFFECT

\begin{tabular}{|l|l|l|l|l|l|}
\hline value & inclination & happiness & Security & satisfaction & total \\
\hline occurrence & 3 & 4 & 4 & 3 & 14 \\
\hline proportion & $21.4 \%$ & $28.6 \%$ & $28.6 \%$ & $21.4 \%$ & $100 \%$ \\
\hline
\end{tabular}

From the above data, what can be seen is that the inclination, happiness, security and satisfaction all exist in the text. The inclination and satisfaction account for $21.4 \%$ respectively, and the happiness and security account for $28.6 \%$. Positive affect resources are in the text and are achieved through some words expressing affective meaning.

For example, "I believe that with the concerted efforts of our five countries and people from different sectors, there will be bright prospects for our cooperation and for the development of BRICS countries". (From http: // www. China daily.com.cn/) "Believe" is the security of affect, which is a positive affect word. This shows that President Xi has the confidence to accomplish the common and significant cooperation among five countries. This also shows President Xi's beautiful and wonderful prospects for the future all over the world.

"To conclude, let me take this opportunity to thank other BRICS leaders and friends from the business, think tank, cultural and sports communities for your strong support for China's BRICS chairmanship. My thanks also go to the friends from the media who have been working really hard". (From http: // www. China daily.com.cn/)This sentence expresses President Xi's strong feelings towards BRICS leaders and audiences through two "thank". It also shows that as a chairman country, China has the confidence and determination to accomplish the cooperation and economic development. 
"Good afternoon! It gives me great pleasure to meet with you and give you an overview of the BRICS Summit and the Dialogue of Emerging Market and Developing Countries". (From http: // www. China daily.com.cn/)This sentence employs "pleasure", the nominalization, to express the happiness of affect, through which President Xi expresses his happy feelings towards the Xiamen Summit of BRICS. The "pleasure" is a direct positive affect.

In addition, President Xi states that We BRICS leaders believe that it is in our common interests to deepen political and security cooperation and enhance mutual strategic trust (From http: //www. China daily.com.cn/). Both "believe" and "common interests" express explicitly the positive attitude system. Political and security cooperation among five countries are all beneficial and common interests for BRICS. What is more, "believe" and "interests" are the expression of the security and satisfaction affects.

"China is ready to work with other parties to give full support to South Africa in convening the summit and keep moving BRICS cooperation forward together"(From http: //www. China daily.com.cn/). In this sentence, "be ready to" is the positive expression of inclination affect. The praised is China, which shows that China's support and help to the work of the South Africa next time.

\section{B. The Analysis of Judgment}

TABLE 3.2

THE DISTRIBUTION OF JUDGMENT

\begin{tabular}{|l|l|l|l|l|l|l|}
\hline & \multicolumn{2}{|l|}{ Social esteem } & Social sanction & \\
\hline value & normality & capacity & tenacity & veracity & propriety & total \\
\hline occurrence & 6 & 4 & 8 & 1 & 3 & 22 \\
\hline proportion & $27.3 \%$ & $18.2 \%$ & $36.4 \%$ & $4.5 \%$ & $13.6 \%$ & $100 \%$ \\
\hline
\end{tabular}

From the above data, what are clear is that there are 22 judgment resources in all in this text, of which there are 18 social esteem and 4 social sanction. Besides, normality and tenacity take the relatively high percentage with $27.3 \%$ and $36.4 \%$. In addition, propriety accounts for $13.6 \%$ and veracity takes up $4.5 \%$, which is the least. Capacity takes up $18.2 \%$ in the total amount. From this analysis, we can see that social esteem is the most, but social sanction is the least in the judgment resources. The following is the examples that analyze the judgment resources.

"The BRICS Xiamen Summit was concluded successfully yesterday" (From http: //www. China daily.com.cn/). In this sentence, the praised is the BRICS Xiamen Summit. The "successfully" is an adverb as the capacity of judgment resources, which shows the success of the BRICS Xiamen Summit. So President Xi gave the high praise towards the BRICS Xiamen Summit.

"The Summit adopted the BRICS Leaders Xiamen Declaration, which reaffirmed the BRICS spirit of openness, inclusiveness and win-win cooperation, reviewed the successful experience of BRICS cooperation over the past decade, and mapped out a new blueprint for strengthening BRICS partnership and deepening practical cooperation across the board"(From http: //www. China daily.com.cn/). In this long sentence, there are kinds of parts of speech, adjectives, verbs, etc. to show the judgment resources. The praised is the behavior, the cooperation of five countries. President $\mathrm{Xi}$ applied the "win-win, successful, strengthen and deepen" to show this cooperation, which expresses President Xi's important attention towards the cooperation of five countries.

"Leaders are determined to take the Xiamen Summit as a new starting point, renew the commitment and work even harder for a closer, broader and more comprehensive strategic partnership and for another "Golden Decade" of BRICS cooperation". (From http: //www. China daily.com.cn/) President Xi employed the "are determined, even harder" to express his attitude to the Xiamen Summit and the partnership of five countries. China has the confidence and determination to promote the development of BRICS.

"It is a fine tradition for BRICS to conduct dialogue and cooperation with other emerging market and developing countries. Under the current circumstances, such dialogue and cooperation have become all the more important" (From http: //www. China daily.com.cn/). In this sentence, the judgment resource is the "more important", and the evaluated is the dialogue and cooperation. Through this word, it is especially clear that such dialogue and cooperation play a significant role in the emerging market and developing countries.

\section{The Analysis of Appreciation}

TABLE 3.3

THE DISTRIBUTION OF APPRECIATION

\begin{tabular}{|l|l|l|l|l|}
\hline value & reaction & composition & Valuation & Total \\
\hline occurrence & 20 & 7 & 18 & 45 \\
\hline proportion & $44.4 \%$ & $15.6 \%$ & $40 \%$ & $100 \%$ \\
\hline
\end{tabular}

The above table is the distribution of appreciation resources respectively. Appreciation is composed of reaction, composition and valuation. In the President Xi' s remarks of the Xiamen Summit, reaction accounts for $44.4 \%$ in all appreciation resources, composition $15.6 \%$ and valuation $40 \%$. The reaction takes up the most proportion and the proportion of composition is the least in three appreciation resources. These data show President Xi's high and positive appreciation towards the partnership and cooperation of five countries. The following is the examples of analyzing the 
appreciation resources.

President Xi emphasized: "We BRICS leaders believe that the world today is undergoing profound and complex changes. While the world economic outlook is improving, all sorts of global challenges continue to emerge"(From http: //www. China daily.com.cn/). Two adjectives - profound and complex are used to show the appreciation of world changes in the background of globalization. They belong to the positive valuation of appreciation resources. Through this appreciation, he gave the overview of globalization with the conflict of economic development and kinds of challenges.

And President Xi also said: "We BRICS leaders believe that the long history and splendid culture of our respective countries are our valued assets and must be cherished"(From http: //www. China daily.com.cn/). In the above sentence, the praised is history and culture of five countries. The two adjectives - long and splendid belong to the reaction of appreciation resources. He emphasized that the history and culture is the basis of cooperation and the development of partnership. At the same time, we are supposed to establish cultural mutual belief institution and mutually develop in the backdrop of globalization.

At the same time, President Xi indicated that: "Since the start of this year, we have had in-depth exchanges of views and reached important consensus on some issues such as the international situation, global governance, international and regional hotspots, national security and development" (From http: //www. China daily.com.cn/). The praised is the consensus on some international issues. The adjective "important" is the positive valuation of appreciation resources, which shows that China dedicated to solve international issues and achieved national security and development with BRICS five countries.

"The summit adopted the BRICS Leaders Xiamen Declaration, which reaffirmed the BRICS spirit of openness, inclusiveness and win-win cooperation, reviewed the successful experience of BRICS cooperation over the past decade, and mapped out a new blueprint for strengthening BRICS partnership and deepening practical cooperation across the board" (From http: //www. China daily.com.cn/). In this sentence, President Xi applied varieties of attitude resources, judgment and appreciation to show his attitude and thinking. The positive appreciation-new is used and the praised is blueprint for the fruitful cooperation of five countries, which shows that China and President Xi are eager for the blueprint of the cooperation of five countries.

At last, President Xi mentioned as well, together, we can blaze a sustainable path featuring innovative, coordinated, green, open and shared development and inject more positive energy to global growth and shared prosperity (From http: //www. China daily.com.cn/). The appreciation systems are realized by means of these words, "sustainable, innovative, coordinated, green, open, shared and positive". The evaluated is the path, development and energy, which shows the spirit and idea of development among five countries.

\section{FINDINGS AND FURTHER RESEARCHES}

Through the analysis of attitudinal resources of President Xi's remarks at the press Conference of BRICS Xiamen Summit from the Perspective of Appraisal Theory, the author reached some findings. Firstly, a large amount of attitudinal resources are stored in President Xi's remarks including affect, judgment and appreciation towards this cooperation and further cooperation. In addition, this paper analyzes the attitudinal resources, so the engagement and graduation can be studied in the further researches. Secondly, the judgment and appreciation resources are far beyond the affect resources, which shows that public speech and remarks should lessen to express personal attitude and feelings. Therefore, the fact is that heavy usage of affect will construct the text too personalized and improper for the kind of serious and factual topic. There will little opportunities to reveal personal affective words. What is more, we are supposed to try our best to use positive attitude not negative ones. Thirdly, there are different parts of speech (adjective, adverb, verb, noun...) to show the attitudinal resources in this discourse, such as successfully, strengthen, pleasure, profound, balanced, etc. Besides, there are much more explicit expressions than implicit expressions in President Xi's remarks at the press conference of BRICS Xiamen Summit. From these we can see that President Xi's definite attitude and persistent decision towards the cooperation and common development of BRICS. In addition, the comparison between China's leader's speech and other countries' leader speech can be studied and researched. Fourthly, although the author tries her best to make the paper as less subjective as possible, it still may be impossible to be actually objective. It is because of cultural and ideological ideas of the appraisal theory.

\section{CONCLUSION}

In the August of 2017, the 9th BRICS Summit has been successfully conducted in Xiamen, China. As we all know, the $3^{\text {rd }}$ BRICS Summit also was held in China, which is significant and meaningful for China's development and improvement of international status. However, analyzing President Xi's remarks at the press conference of BRICS Xiamen Summit from the point of the Appraisal Theory is greatly beneficial. In the process of studying these attitudinal resources, we know that the explicit and positive attitudes are far beyond the implicit and negative ones, and judgment and appreciation resources are much more than affect ones. From the analysis of this text, we can learn the meaningfulness of cooperation among different countries. As President Xi said, We BRICS leaders believe that practical cooperation is the root of BRICS cooperation. A tree will only flourish when its root goes deep. We will, in line with the 
principle of mutual benefit, step up macro policy coordination, synergize development strategies and deepen all-round cooperation in areas such as economy, trade, finance, industry and sustainable development so as to bring about interconnected development(From http: //www. China daily.com.cn/). Therefore, the analysis of President Xi's remarks at the press conference of Xiamen BRICS Summit is greatly beneficial for the construction of China's image. Based on this, this paper analyzed the attitudinal resources of President Xi's remarks and calculated its distributions that make contributions to the researches of China's image to some extent. Through the attitudinal analysis, we can know the China's attitude towards the common development and cooperation and the background of development and cooperation. In the end, this paper wishes to make some contributions to the researches of the Appraisal Theory especially positive discourse analysis to some extent.

\section{REFERENCES}

[1] Li Chenchen \& Jiang Guiying. (2017). A comparative study of Chinese and English academic studies from the perspective of theoretical attitude system. Foreign Language Education, 5, 43-48.

[2] Li Zhanzi. (2002). Interpersonal Meaning Research of Discourse. Shanghai: Shanghai Foreign Language Education Press.

[3] Martin J.R. (2000). "Beyond Exchange: Appraisal Systems in English." Evaluation in Text: Authorial Stance and the Construction of Discourse. Ed. S. Hunston and G. Thompson. Oxford: Oxford University Press.

[4] Martin, J. R., and David Rose. (2003). Working with Discourse: Meaning Beyond the Clause. London: Continuum.

[5] Martin, J.R., and P.R.R. White. (2008). The Language of Evaluation: Appraisal in English. Beijing: Foreign Language Teaching and Research Press.

[6] Painter, C. (2003). 'Developing attitude: An Ontogentic Perspective On Appraisal'. Text 23.2. 183-210.

[7] Wang Yuelu. (2016). The analysis of attitudinal meaning from the point of view of Appraisal Theory. Ability and Wisdom, 28, 219-220.

[8] Wang Zhenhua. (2001). The Appraisal System-The New Development of Systematic Functional Linguistics. Foreign Language, $13-15$.

[9] Xinhua. (2017). Full text of President Xi's remarks at press conference of BRICS Xiamen Summit. http: // www. China daily.com.cn/. (accessed 06/09/2017).

Yuyu Zhang was born in Shanxi, China in 1993. She is now learning in Shanxi Normal University, as a graduate student for a Master's degree. Her research interests are in pragmatics and language teaching. She will get master's degree in 2019. 